\title{
Gospodarske i ampelografske karakteristike autohtonih sorata kastavskog područja
}

\section{Sažetak}

Unazad nekoliko godina na području grada Kastva nekolicina proizvođača grožđa $i$ vina u suradnji sa znanstvenim institucijama $i$ uz potporu lokalnih jedinica uprave $i$ samouprave nastoji obnoviti vinogradarsku proizvodnju temeljenu na autohtonom sortimentu. Prvi korak već je napravljen identifikacijom nekoliko autohtonih sortata. Sorte Jarbola, Verdić, Mejsko belo, Divjaka i Brajkovac su nakon identifikacije razmnožene i posađene u zasad manjim nasadima lokalnih vinogradara. Cilj ovog rada bio je utvrditi osnovne gospodarske i ampelografske karakteristike navedenih sorata u proizvodnom nasadu lokalnih proizvođača. Analizom podataka utvrđen je broj grozdova po trsu, prinos po trsu, mehanički sastav grozda i kemijski sastav mošta. Na taj način utvrđene su osnovne razlike između sorata kao i gospodarski potencijal svake sorte. Sorta Verdić ima dimenzijama i masom najveći grozd, dok sorta Brajkovac dimenzijama i masom ima najmanji grozd. Sorta Jarbola ima najveću masu bobice i najveći udio mesa u masi grozda te izrazito veliki broj grozdova po trsu. Sorta Divjaka se odlikuje visokom rodnošću te najmanjom masom bobica. Sorte Mejsko belo i Brajkovac pokazale su se, zbog visokog sadržaja šećera, kao sorte s najboljim kvalitativnim potencijalom u promatranoj godini istraživanja.

Ključne riječi: autohtone sorte, vinova loza, Kastav, ampelografska istraživanja, gospodarska svojstva

\section{Uvod}

Područje grada Kastva, u 19. stoljeću kao i šire područje kvarnerskog zaljeva bili su tipični vinogradarski kraj. O proizvodnji grožđa na području kastavštine detaljno pišu Dorčić i Tomašić (1931) pri čemu navode da su se slično kao i na području grada Bakra krajem 19. stoljeća za potrebe uzgoja vinove loze gradile terase od suhozida (Maletić $i$ sur., 2014). Također, isti autori navode da je na području Kastva 1930. godine bilo 983 hektara vinograda s kojih se proizvelo 2.454 hektolitara vina (Maletić i sur., 2014). Danas je prema službenim statistikama na području čitave vinogradarske podregije Hrvatsko primorje registrirano svega 246 ha vinograda, a prijavljena količina vina 16.061 hektolitara vina (www.apprrr.hr, 2016). Temeljem navedenoga može se zaključiti da je u prošlosti proizvodnja grožđa i vina bila značajna gospodarska grana, a trgovina vinom značajan izvor prihoda za stanovnike Kastavštine, ali i čitavog Kvarnera.

Pojava bolesti i štetnika vinove loze krajem 19. i početkom 20. stoljeća, kao i snažan i kontinuirani razvoj industrijske proizvodnje i pomorstva u obližnjoj Rijeci, uvjetovali su na ovom strmom i škrtom kraškom području napuštanje vinogradarske i poljoprivredne proizvodnje općenito. Inicijativom lokalnih proizvođača grožđa i vina i njihovom željom za obnovom tradicije vinogradarstva i vinarstva na području Kastavštine uspostavljena je, uz potporu lokalnih tijela uprave i samouprave, suradnja s Agronomskim fakultetom. Aktivnostima identifikacije i inventarizacije sorata u starim stoljetnim nasadima potvrđeno je postojanje pet autohtonih sorata kastavskog područja: Mejsko belo, Verdić, Divjaka, Jarbola i Brajkovac. Ovime su navedene sorte u zadnji čas spašene od negativnog trenda njihovog izumiranja karakterističnog za čitavo područje Republike Hrvatske. Sve pronađene sorte namijenjene su proizvodnji bijelih vina.

U mnogim povijesnim dokumentima osim općih značajki vinogradarstva i vinarstva spominje se i veliki broj sorata koje su se uzgajale na području čitavoga Kvarnera, a danas su utvrđene 
na području Kastva. Tako član Gospodarskog društva, Mijat Sabljar, u Gospodarskim novinama br. 3. i 4. iz 1853. spominje sorte Verdić i Brajkovac (Maletić i sur., 2014). Sorta Verdić pod sinonimima Prosecco tondo i Glera danas je vrlo raširena u sjevernoj Italiji i predstavlja dominantnu sortu za proizvodnju glasovitog biser vina Prosecco. Sladonja i sur. (2007) navode kako najstariji zapis o sorti Jarbola datira s kraja 19 st. u djelima pisca Franje Matetića. Sorte Divjaka i Mejsko belo na ovim prostorima spominje tek Vitolović u djelu Vinogradarstvo istre iz 1960-te.

Daljnjim znanstvenim istraživanjima potrebno je u novim nasadima navedenih sorata utvrditi njihove agrobiološke i gospodarske karakteristike radi prilagodbe tehnologije uzgoja suvremenim trendovima u proizvodnji grožđa i vina.

\section{Materijali i metode}

Ovim istraživanjem utvrđene su ampelografske i gospodarske karakteristike pet sorata kastavskog područja. Ampelografske metode uključuju uvometrijsku i mehaničku analizu grožđa i bobica dok su gospodarske karakteristike utvrđene mjerenjem ukupnog prinosa i broja grozdova po trsu te osnovnim kemijskim sastavom mošta.

Pokusni nasad nalazi se na području grada Kastva. Nasad je starosti sedam godina, razmak sadnje između redova je 150, a unutar reda $90 \mathrm{~cm}$. Sustav uzgoja je jednostruki Guyot. Grožđe svih sorata u istraživanju koristi se isključivo za proizvodnju bijelih vina, odnosno radi se o „bijelim sortama" grožđa.

Istraživanje je provedeno 2016. godine u jesen u trenutku tehnološke zrelosti grožđa . Radi se prvoj godini istraživanja. U vinogradu su odabrana tri trsa od svake sorte. Odabrani su trsovi ujednačene bujnosti i primjenjenim istim ampelotehničkim mjerama. Na trsevima je brojenjem utvrđen ukupni broj grozdova po trsu, a vaganjem grozdova, prinos po svakom trsu. Iz ukupne mase grožđa sa sva tri trsa jedne sorte, nasumičnim odabirom, uzorkovano je 10 grozdova za daljnju laboratorijsku analizu. Laboratorijska analiza uključuje uvometrijske analize koje podrazumjevaju mjerenje dimenzija i mase grozdova i bobica (Maletić $i$ sur., 2008) te analizu mehaničkog sastava grozda prema modificiranoj metodi po Prostoserdovu (1946). Na osnovi mehaničke analize izračunat je udio peteljkovine, mesa, kožica te sjemenki u grozdu. Na navedenom uzorku također je provedena osnovna kemijska analiza mošta koja podrazumjeva: sadržaj šećera $\left(\mathrm{Oe}^{0}\right)$ i ukupnih kiselina $\left(\mathrm{gL}^{-1}\right)$ te $\mathrm{pH}$ vrijednost mošta. Broj grozdova, prinos po trsu i parametri kemijske analize predstavljaju direktne gospodarske karakteristike.

Podaci dobiveni istraživanjem statistički su obrađeni korištenjem statističkog softvera SAS System Software, v. 9.3. (SAS Institute Inc., Cary, NC, USA, 2012). Statistička analiza uključuje deskriptivnu statistiku (prosječna, minimalna i maksimalna vrijednost) te analizu varijance $\mathrm{i}$ usporedbu srednjih vrijednosti (Duncans multiple-range test).

\section{Rezultati i rasprava}

\section{Uvometrijska istraživanja i mehanički sastav grozda}

Uvometrijskom analizom grožđa između sorata Verdić, Mejsko belo, Jarbola, Divjaka i Brajkovac utvrđene su značajne razlike u svim promatranim parametrima (Tablica 1.). Prema svim osnovnim uvometrijskim parametrima najveće prosječne vrijednosti utvrđene su kod sorte Verdić. Sorta Verdić tako je imala najveću dužinu $(214,07 \mathrm{~mm})$, širinu $(149,94 \mathrm{~mm})$ te masu grozda (323,7 g). Također ova sorta imala je i najveću masu bobica $(301,5 \mathrm{~g})$ i peteljkovine $(22,19 \mathrm{~g})$. Kod sorte Brajkovac, suprotno sorti Verdić, utvrđene su najmanje vrijednosti. Dužina grozda kod ove sorte iznosila je 110,26 mm, širina 77,9 mm, a masa grozda 138,57 g. Masa bobica iznosila je kod ove sorte $132,08 \mathrm{~g}$, a masa peteljkovine $6,48 \mathrm{~g}$.

Analizom srednjih vrijednosti sorata Mejsko belo, Jarbola i Divjaka utvrđeno je da se nalaze između sorata Verdić i Brajkovac. Statistička razlika između ovih triju sorata međusobno utvr- 
đena je jedino kod svojstva širine grozda pri čemu je najveću širinu imala sorta Mejsko belo $(116,96 \mathrm{~mm})$, a najmanju Divjaka $(85,85 \mathrm{~mm})$. Kod parametara dužine grozda, mase grozda, mase bobica i mase peteljke nisu utvrđene signifikantne razlike.

Tablica 1. Rezultati uvometrijske analize i mehaničkog sastava grozda/ Table 1. Results of the uvometric analysis and the mechanical composition of the cluster

\begin{tabular}{lccccc}
\hline Sorta & $\begin{array}{c}\text { Dužina grozda } \\
(\mathrm{mm})\end{array}$ & $\begin{array}{c}\text { Širina grozda } \\
(\mathrm{mm})\end{array}$ & $\begin{array}{c}\text { Masa grozda } \\
(\mathrm{g})\end{array}$ & $\begin{array}{c}\text { Masa bobica } \\
(\mathrm{g})\end{array}$ & $\begin{array}{c}\text { Masa peteljkovine } \\
(\mathrm{g})\end{array}$ \\
\hline Verdić & $214,07 \mathrm{a}^{*}$ & $149,94 \mathrm{a}$ & $323,7 \mathrm{a}$ & $301,5 \mathrm{a}$ & $22,19 \mathrm{a}$ \\
\hline Mejsko belo & $152,39 \mathrm{~b}$ & $116,96 \mathrm{~b}$ & $252,35 \mathrm{~b}$ & $241,18 \mathrm{~b}$ & $11,16 \mathrm{~b}$ \\
\hline Jarbola & $139,93 \mathrm{~b}$ & $100,43 \mathrm{bc}$ & $212,82 \mathrm{~b}$ & $202,99 \mathrm{~b}$ & $9,83 \mathrm{~b}$ \\
\hline Divjaka & $138 \mathrm{~b}$ & $85,85 \mathrm{~cd}$ & $210,58 \mathrm{~b}$ & $198,41 \mathrm{~b}$ & $12,17 \mathrm{~b}$ \\
\hline Brajkovac & $110,26 \mathrm{c}$ & $77,9 \mathrm{~d}$ & $138,57 \mathrm{c}$ & $132,08 \mathrm{c}$ & $6,48 \mathrm{c}$ \\
\hline
\end{tabular}

*Srednje vrijednosti označene različitim slovima između sorata razlikuju se statistički značajno uz $p<0,05$ korištenjem Duncan's multiple range test

Analizirajući podatke iz tablice za svaku sortu pojedinačno, možemo zaključiti da prema svim promatranim parametrima sorta Verdić posjeduje najveći, a sorta Brajkovac najmanji grozd.

Statističkom analizom mehaničkog sastava bobica također su utvrđene značajne razlike između sorata (Tablica 2). Valja napomenuti da su vrijednosti izražene na razini 50 bobica zbog lakše interpretacije dobivenih rezultata. Ekvivalentne razlike utvrđene su i na razini jedne bobice.

Statističkom analizom utvrđeno je da se sorte Jarbola, Brajkovac i Mejsko belo značajno razlikuju od sorata Divjaka i Verdić. Pri tome je prosječno najveća masa 50 bobica utvrđena kod sorte Jarbola $(104,03$ g), a najmanja kod sorte Divjaka $(70,1 \mathrm{~g})$. Statistički najveća masa kožice utvrđena je kod sorte Brajkovac (9,61 g), a najmanja kod sorte Verdić $(4,05 \mathrm{~g})$. Najveću masu 50 sjemenki imale su sorte Verdić $(2,76 \mathrm{~g})$ i Brajkovac (2,63 g), a najmanju Jarbola (1,62 g). Masa mesa 50 bobica statistički je bila najveća kod sorte Jarbola $(97,3 \mathrm{~g})$, a najmanja kod sorata Verdić $(66,35 \mathrm{~g})$ i Divjaka $(63,75 \mathrm{~g})$.

Tablica 2. Mehanička analiza bobica/Table 2. Mechanical analysis of berry

\begin{tabular}{lcccc}
\hline Sorta & $\begin{array}{c}\text { Masa } 50 \text { bobica } \\
(\mathrm{g})\end{array}$ & $\begin{array}{c}\text { Masa kožica } 50 \text { bobica } \\
(\mathrm{g})\end{array}$ & $\begin{array}{c}\text { Masa sjemenki } 50 \text { bobica } \\
(\mathrm{g})\end{array}$ & $\begin{array}{c}\text { Masa mesa } 50 \text { bobica } \\
(\mathrm{g})\end{array}$ \\
\hline Verdić & $73,17 \mathrm{~b}$ & $4,05 \mathrm{~d}$ & $2,76 \mathrm{a}$ & $66,35 \mathrm{c}$ \\
\hline Mejsko belo & $94,61 \mathrm{a}^{*}$ & $7,93 \mathrm{~b}$ & $1,97 \mathrm{bc}$ & $84,7 \mathrm{~b}$ \\
\hline Jarbola & $104,03 \mathrm{a}$ & $5,1 \mathrm{c}$ & $1,62 \mathrm{c}$ & $97,3 \mathrm{a}$ \\
\hline Divjaka & $70,1 \mathrm{~b}$ & $4,21 \mathrm{~d}$ & $2,14 \mathrm{~b}$ & $63,75 \mathrm{c}$ \\
\hline Brajkovac & $101,53 \mathrm{a}$ & $9,61 \mathrm{a}$ & $2,63 \mathrm{a}$ & $89,31 \mathrm{ab}$ \\
\hline
\end{tabular}

*Srednje vrijednosti označene različitim slovima između sorata razlikuju se statistički značajno uz $p<0,05$ korištenjem Duncan's multiple range test 
Analizirajući podatke iz Tablice 2. za svaku sortu pojedinačno, možemo zaključiti da je sorta Brajkovac u najvećem broju parametara bila statistički značajno različita u odnosu na druge sorte. Sorta Brajkovac statistički je sorta s najvećom masom bobice i najvećom masom mesa, što je i logično obzirom da meso zauzima i najveći udio u sastavu bobice. Masa sjemenke kod ove sorte bila je, također, odmah iza Verdića, dok je masa kožice parametar koji je kod ove sorte bio signifikantno najveći. Također valja spomenuti da je sorta Verdić, koja je po karakteristikama grozda imala najveće vrijednosti, kod parametara mehaničkog sastava bobice masa bobice i masa mesa bobice imala najmanje vrijednosti. Verdić je imao i najmanju masu kožice dok je u odnosu na ostale sorte imao najveću masu sjemenke.

Mehaničkom analizom utvrđeni su udjeli pojedinih dijelova grozda u ukupnoj masi grozda (Tablica 3.). Analizom je utvrđeno da najveći udio peteljkovine u grožđu ima sorta Verdić $(6,84$ \%) dok najmanji udio imaju sorte Mejsko belo, Jarbola i Brajkovac od kojih prosječno najmanji udio ima Mejsko belo (4,42\%). Najveći udio mesa u masi grozda ima sorta Jarbola (89,17\%), a najmanji sorta Brajkovac (83,85\%). Kod sorte Brajkovac s druge strane utvrđen je najveći udio kožice u masi grozda (9,02 \%) dok je najmanji udio utvrđen kod sorte Jarbola (4,67 \%). Kod sorte Verdić utvrđen je najveći udio sjemenki (3,51 \%) , anajmanji kod sorte Jarbola (1,48 \%).

Tablica 3. Udjeli pojedinih sastavnica u ukupnom sastavu grozda/ Table 3 . The shares of individual constituents in the total cluster composition

\begin{tabular}{lcccc}
\hline Sorta & \multicolumn{4}{c}{ Udio pojedinih dijelova grozda u ukupnoj masigrozda } \\
\hline Verdić & Peteljkovina (\%) & Meso (\%) & Kožica (\%) & Sjemenke (\%) \\
\hline Mejsko belo & $6,84 \mathrm{a}$ & $84,47 \mathrm{c}$ & $5,15 \mathrm{~d}$ & $3,51 \mathrm{a}$ \\
\hline Jarbola & $4,42 \mathrm{c}$ & $85,55 \mathrm{~b}$ & $8,01 \mathrm{~b}$ & $1,98 \mathrm{~d}$ \\
\hline Divjaka & $4,65 \mathrm{c}$ & $89,17 \mathrm{a}$ & $4,67 \mathrm{e}$ & $1,48 \mathrm{e}$ \\
\hline Brajkovac & $5,7 \mathrm{~b}$ & $85,74 \mathrm{~b}$ & $5,66 \mathrm{c}$ & $2,87 \mathrm{~b}$ \\
\hline
\end{tabular}

*Srednje vrijednosti označene različitim slovima između sorata razlikuju se statistički značajno uz $p<0,05$ korištenjem Duncan's multiple range test

Izračunom i analizom udjela pojedinih dijelova grozda u njegovom sastavu možemo dobiti najbolji uvid u strukturu grozda. Na ovaj način, s gospodarskog gledišta možemo napraviti procjenu koja će od sorata prema udjelu mesa imati veliki udio tekuće faze odnosno mošta u masi grozda. Također, sorte s većim udjelom sjemenke ili kožice u masi grozda imaju potencijalno veći sadržaj polifenolnih spojeva što je osobito važno kod proizvodnje crnih vina.

Analizom promatranih sorata u Tablici 3. možemo zaključiti da sorte koje značajno odstupaju od prosjeka, u dosadašnjim analizama pokazuju slične trendove i u udjelima pojedinih sastavnica u ukupnoj masi grozda. Sorta Verdić jedna je od sorata s najmanjim udjelom mesa u grozdu te najmanjim udjelom kožice dok u odnosu na ostale sorte ima najveći udio sjemenki i peteljkovine u masi grozda. Sorta Brajkovac je u ukupnoj masi grozda imala najmanji udio mesa, ali i značajno najveći udio kožice. Veliki udio kožice pozitivan je s tehnološkog aspekta proizvodnje bijelih vina jer je glavnina aromatskih tvari smještena upravo u kožici bobice (Maletić i sur., 2008). Sorta Jarbola imala je najveći udio mesa u masi grozda dok je udio kožice kao i sjemenki bio signifikantno najmanji. Mehaničkom analizom (Tablica 2.) utvrđeno je da ova sorta posjeduje i najveću masu bobice uz istovremeno sinifikantno najmanju masu kožica i sjemenki. Iz navedenoga možemo pretpostaviti da ova sorta u proizvodnje po kilogramu grožđa može dati najveću količinu mošta. 


\section{Gospodarske karakteristike}

Gospodarske karakteristike uključuju mjerenje broja grozdova po trsu, prosječnog prinosa po trsu te kemijski sastav mošta dobivenoga nakon postupka tiještenja u laboratoriju odnosno runjenja i muljanja u tijeku procesa proizvodnje grožđa.

Analizom broja grozdova po trsu nisu utvrđene statistički opravdane razlike između sorata iako je najveći prosečni broj grozdova po trsu imala sorta Jarbola $(19,33)$, dok je najmanji broj grozdova imala sorta Mejsko belo $(10,66)$ (Tablica 4). Najveći prinos po trsu imala je sorta Verdić $(4,05 \mathrm{~kg})$, a najmanji sorte Divjaka (2,6 kg), Brajkovac (2,13 kg) i Mejsko belo (2,1 kg).

Kemijskom analizom mošta utvrđeni su osnovni parametri kvalitete mošta (Tablica 4.). Najviše šećera sadržavala je sorta Brajkovac $\left(84 \mathrm{Oe}^{0}\right)$, a najmanje sorte Verdić $\left(66 \mathrm{Oe}^{0}\right)$ i Divjaka (66 $\left.\mathrm{Oe}^{0}\right)$. Najveća koncentracija ukupnih kiselina u trenutku pune zrelosti utvrđena je kod sorte Jarbola $\left(9,12 \mathrm{gL}^{-1}\right)$, a najmanja kod sorte Mejsko belo $\left(5,6 \mathrm{gL}^{-1}\right)$. Najveća $\mathrm{pH}$ vrijednost utvrđena je kod sorte Brajkovac $(3,24)$ a najniža kod sorte Jarbola $(3,0)$.

Tablica 4. Rezultati mjerenja gospodarskih svojstava sorata/ Table 4. Results of measurement of the commercial properties of varieties

\begin{tabular}{lccccc}
\hline & Broj grozdova po trsu & Prinos po trsu $(\mathrm{kg})$ & Šećer $\left(\mathrm{Oe}^{0}\right)$ & Kiseline $\left(\mathrm{gL}^{-1}\right)$ & $\mathrm{pH}$ \\
\hline Verdić & $11,66 \mathrm{a}$ & $4,05 \mathrm{a}$ & 66 & 6,2 & 3,05 \\
\hline Mejsko belo & $10,66 \mathrm{a}$ & $2,1 \mathrm{~b}$ & 80 & 5,6 & 3,12 \\
\hline Jarbola & $19,33 \mathrm{a}$ & $3,34 \mathrm{ab}$ & 67 & 9,12 & 3,0 \\
\hline Divjaka & $14 \mathrm{a}$ & $2,6 \mathrm{~b}$ & 66 & 8,89 & 3,02 \\
\hline Brajkovac & $14 \mathrm{a}$ & $2,13 \mathrm{~b}$ & 84 & 7,01 & 3,24 \\
\hline
\end{tabular}

*Srednje vrijednosti označene različitim slovima između sorata razlikuje se statistički značajno uz $p<0,05$ korištenjem Duncan's multiple range test

Analizom parametara koji daju uvid u gospodarska svojstva možemo utvrditi da je kod sorata Verdić, Jarbola i Divjaka došlo do slabijeg nakupljanja šećera (oko $67 \mathrm{Oe}^{0}$ ) kao i veće ukupne kiselosti u moštu (8,89 $\mathrm{gL}^{-1}$ Divjaka i $9,12 \mathrm{gL}^{-1}$ Jarbola) što je s aspekta uvjeta za proizvodnju kvalitetnog vina nedovoljno (alkoholna jakost minimalno $10.5 \%$ volumnih alkohola i 5-6 $\mathrm{gL}^{-1}$ kiselina). Da bi se proizvelo vino s navedenim parametarima sadržaj šećera u moštu trebao bi biti minimalno $78 \mathrm{Oe}^{0}$, a koncentracija kiselina u moštu 6-7 gL $\mathrm{gL}^{-1}$. Razlog ovako nepovoljnim kvalitativnim pokazateljima svakako leži i u kvantitativnim pokazateljima, a to je prije svega prinos grožđa, koji u slučaju Verdića, Jarbole i Divjake prelazi 2,5 kilograma, što je više od preporučenih do $2 \mathrm{~kg}$ za proizvodnju kvalitetnih vina. Uzrok visokom prinosu najčešće leži u velikom broju grozdova što i je slučaj kod sorata Jarbola i Divjaka, ali i u velikoj masi grozda što je slučaj kod sorte Verdić. lako je Verdić prema svim pokazateljima mehaničkog sastava grozda bio sorta s najmanjim udjelom mesa u sastavu bobica i grozda, zbog velikog grozda i visoke rodnosti ipak može dati i veliku količinu mošta.

Kvalitativno najbolje vrijednosti pokazale su sorte Mejsko belo i Brajkovac. Sorta Brajkovac, iako je imala veliki broj grozdova, zbog male mase grozda i niskog udjela mesa u grozdu imala je jedan od najmanjih i tehnološki prihvatljivih prinosa od svega 2,13 kg po trsu. Ovakvi parametri uz ostale adekvatne ampelotehničke mjere u vinogradu dovoljni su za postizanje dobre kvalitete mošta, a kasnije i vina. Sorta Mejsko belo također je uz dobru rodnost i optimalan prinos dala dobre rezultate prema pokazateljima kvalitete. Prema prethodnim analizama pokazalo se da ova sorta odmah iza Verdića ima najveći grozd. Udio mesa bio je kao i kod većine sorata (85,55\%), ali s većim udjelom kožice u masi grozda (8,01\%), odmah iza Brajkovca. Dobre rezultate u kvalitativnim pokazateljima kod sorata Mejsko belo i Brajkovac možemo pripisati 
optimalnom prinosu, ali uz pretpostavku dobrog genetskog potencijala samih sorata za nakupljanje šećera. Kako bi točno utvrdili da li su navedeni rezultati posljedica genetskog potencijala sorte, tehnologije uzgoja ili klimatskih faktora, na navedenom području biti će potrebno provesti dodatna višegodišnja istraživanja.

\title{
Zaključak
}

Analizom uvometrijskih i gospodarskih parametara sorata Verdić, Mejsko belo, Jarbola, Divjaka i Brajkovac utvrđene su značajne razlike među sortama. Tako sorta Verdić ima dimenzijama i masom najveći grozd, dok sorta Brajkovac dimenzijama i masom ima najmanji grozd. Sorta Brajkovac posjeduje i najmanji udio mesa u masi grozda te najveći udio kožice kao i veliki broj grozdova po trsu. Sorta Jarbola ima najveću masu bobice i najveći udio mesa u masi grozda te izrazito veliki broj grozdova po trsu. Sorta Divjaka se odlikuje visokom rodnošću te najmanjom masom bobica. Sorte Mejsko belo i Brajkovac pokazale su se, zbog visokog sadržaja šećera, kao sorte s najboljim kvalitativnim potencijalom. Dobiveni rezultati dali su bolji uvid u agrobiološka svojstva navedenih sortata koja su dosad bila u potpunosti neistražena. S gospodarskog gledišta, dobiven je jasan uvid u mogućnost primjene pojedinih tehnoloških postupaka u vinogradu s ciljem optimiziranja prinosa i postizanja bolje kvalitete mošta. Treba naglasati da se radi o jednogodišnjem istraživanju stoga bi za konačnu potvrdu dobivenih rezultata u navedenim okolišnim uvijetima trebalo provesti dodatna, višegodišnja istraživanja.

\section{Literatura}

Dorčić I, Tomašić, M., (1931) Kastav i Kastavština u prošlosti i sadašnjosti. Odbor za proslavu 10. god. oslobođenja Kastavštine (1921-1931. Tiskara Dragutina Spuller, Samobor).

Gospodarske novine br. 3 .i 4. (1853) Digitalizirana arhiva Gospodarskog lista (http://digital.arhivpro.hr/sdb1/gospodarski_list4/)

Maletić, E., Karoglan Kontić, J., Pejić, I. (2008) Vinova loza-ampelografija, ekologija, oplemenjivanje. Zagreb: Školska knjiga

Maletić, E., Pejić l., Karoglan Kontić, J., Preiner, D., Šimon, S., Husnjak, S., Andabaka, Ž., Stupić, D., Marković, Z., Žulj Mihaljević, M. (2014) Sorte vinove loze Hrvatskog primorja. Zagreb: Centar za brdsko-planinsku poljoprivredu Primorsko goranske županije, Ravna Gora

Prostoserdov, I.I. (1946) Tehnologičeskae harakteristika vinograda i produktiv ego peredabotki. Moskva: Ampelografia SSSR, Tom I

Sladonja, B., Poljuha, D., Plavša, T., Peršurić, Đ., Crespan, M. (2007) Autochtonous Croatian grapevine cultivar "Jarbola“molecular, morphological and oenological characterization. Vitis, 46 (2), 99-100.

Vinogradarski registar, podaci za 2016. godinu- Agencija za palćanje u poljoprivredi, ribarstvu i ruralnom razvoju (http:// www.apprrr.hr/vinogradarski-registar-1128.aspx)

Vitolović, V. (1960) Vinogradarstvo Istre. Beograd: Savez poljoprivrednih inžinjera i tehničara FNR Jugoslavije

\section{Commercial and ampelographic characteristics of autochthonous grape varieties of Kastav area}

Original scientific paper

\begin{abstract}
Several years ago in the city area of Kastav several grape and wine producers in cooperation with scientific institutions and local-government tried to restore the grape production based on autochthonous grapevine varieties. The first step has already been done by identifying several indigenous varieties. After the identification, Verdić, Mejsko belo, Divjaka, Jarbola and Brajkovac variety were propagated and planted in new vineyards of local producers. The aim of this study was to determine the basic yeald and ampelographic characteristics of mentioned varieties in vineyards of local grepe and wine producers in Kastav. Analysis of the data is determined by the number of bunches per vine, yield per vine, the chemical composition of must and mechanical composition of the cluster and berry. This research set out the basic differences between varieties and economic potential of each variety. Variety Verdić have the largest and variety Brajkovac the smallest dimensions and mass of the cluster. Variety Jarbola have the largest berry mass and the highest proportion of meat in the cluster mass. Also it has a very large number of clusters per vine. The Divjaka variety is distinguished by its high yield-set potential and the smallest mass of berry. The varieties of Mejsko Belo and Brajkovac have higher sugar content and proved to be potentially best-quality varieties in this year of research.
\end{abstract}

Keywords: autochthonous grapevine varieties, V. vinifera L., Kastav, ampelographic research, economical characteristics 